\title{
La prueba
}

Taruffo, Michele. Marcial Pons, Madrid, 2008, 324 p.

(traducción de Laura Manríquez y Jordi Ferrer Beltrán)

Claudio Meneses Pacheco

páginas 449 - 452

\section{LA PRUEBA \\ Taruffo, Michele. Marcial Pons, Madrid, 2008, 324 p. (traducción de Laura Manríquez y Jordi Ferrer Beltrán)}

\author{
Claudio Meneses Pacheco*
}

La obra de Michele Taruffo en el campo de la prueba en juicio ya es conocida entre nosotros, no sólo por la traducción al español que de su principal trabajo hizo Jordi Ferrer hace unos años y que ha permitido a los hispanohablantes acceder a su teoría ${ }^{1}$, sino especialmente por las publicaciones en Chile de varios de sus artículos sobre la materia ${ }^{2}$. De hecho, uno de ellos fue incluido en un número de esta revista: nos referimos, en efecto, a "Poderes probatorios de las partes y del juez en Europa", que -como indicamos en la cita anterior- figura en el número 2 del volumen 12, año 2006. Tenemos, pues, una trayectoria científica que en estos días nos resulta completamente familiar ${ }^{3}$.

Profesor de Derecho Procesal, Universidad de Valparaíso. Becario del Programa de Doctorado, Universidad de los Andes, Chile. Correos electrónicos: claudio.meneses@uv.cl, cmeneses@ mbmack.cl. El autor agradece a los alumnos del programa de legum magister de la Escuela de Derecho de la Universidad de Valparaíso, quienes probablemente sin saberlo- lo han estimulado para redactar esta reseña.

1 Estamos aludiendo a Taruffo, Michele, La prueba de los hechos, trad. J. Ferrer Beltrán, Trotta, Madrid, 2002, cuyo título original es La prova dei fatti giuridice, Giuffrè, Milano, 1992.

2 Véanse en orden cronológico, los siguientes textos: Taruffo, Michele, "Consideraciones sobre verdad y prueba", en AA.VV., La prueba en el nuevo proceso penal, edit. R. Coloma Correa, Lexis Nexis, Santiago, 2003, pp. 163-184; Taruffo, Michele, "Investigación judicial y producción de prueba por las partes", en Revista de Derecho, Universidad Austral, Facultad de Ciencias Jurídicas y Sociales, 2003, vol. 15, N², pp. 205-213; Taruffo, Michele, "Poderes probatorios de las partes y del juez en Europa", en Revista Ius et Praxis, Universidad de Talca, Facultad de Ciencias Jurídicas y Sociales, 2006, vol. 12, N², pp. 95-122; Taruffo, Michele, "Narrativas judiciales", en Revista de Derecho, Universidad Austral, Facultad de Ciencias Jurídicas y Sociales, 2007, vol. 20, N¹, pp. 231-270; Taruffo, Michele, “¿Verdad negociada?”, en Revista de Derecho, Universidad Austral, Facultad de Ciencias Jurídicas y Sociales, 2008, vol. 21, N¹, pp. 129-151.

3 Podemos agregar, asimismo, que se han exhibido otros estudios de este mismo autor, y que ello ha tenido lugar también a través de esta revista. Véase, Taruffo, Michele, "El proceso civil de 'civil law' y de 'common law': aspectos fundamentales", en Revista Ius et Praxis, Universidad de Talca, Facultad de Ciencias Jurídicas y Sociales, 2006, año $12, \mathrm{~N}^{\circ} 1$, pp. 69-94. 
Pero la referencia a este grupo de investigaciones es actualmente incompleta, ya que el año pasado la casa editorial Marcial Pons publicó un nuevo trabajo de este procesalista italiano. Tenemos que hacer, por tanto, otra difusión, esta vez de su más reciente texto, por el cual Taruffo expone en forma ordenada y sintética los principales aspectos de la prueba judicial ${ }^{4}$. Este trabajo está titulado precisamente La prueba y, como dice Ferrer (quien interviene esta vez en calidad de cotraductor y como presentador), corresponde -fundamentalmente- a la voz "prueba" de una enciclopedia. El concepto de la prueba judicial desde una perspectiva eminentemente epistemológica; sus criterios de selección ordenados en torno a las nociones de relevancia y admisibilidad; los tipos de prueba que pueden emplearse en un proceso jurisdiccional; la modalidad procesal a través de la cual se puede presentar la evidencia a una causa judicial y, en fin, la decisión final en el establecimiento de la cuestión fáctica, son tratados en una forma concisa y clara. Nos atrevemos a decir que en un total de ciento cuarenta páginas (pp. 15-155), el lector podrá encontrar una visión de conjunto del pensamiento de Taruffo ${ }^{5}$.

Junto con esta macro mirada del fenómeno probatorio, el texto que comentamos contiene además cinco artículos, contenidos bajo la forma de anexos entre las páginas 159 y 295 . Éstos, empero, no son exposiciones generales sino, por el contrario, constituyen investigaciones muy particulares sobre determinados problemas abiertos a una constante discusión. De este modo, se analiza la compatibilidad que existe entre los poderes de las partes y los del juez en la prueba procesal civil ${ }^{6}$; se estudian a fondo las implicancias que trae consigo una visión holista de la prueba, basada en la coherencia de las narrativas antes que en el contenido epistémico de la información ${ }^{7}$; se profundiza sobre las repercusiones que tienen las soluciones procesales en el campo de la quaestio facti, basadas en las voluntades expresas o tácitas de los litigantes ${ }^{8}$; se examinan los estándares que deben aplicarse en la prueba del nexo causal y, por fin, se reflexiona en torno a la forma como debe ser sospesada la injerencia de la ciencia en el conocimiento judicial de los hechos. Podemos decir que en esta sección de anexos, el lector presenciará una detallada aplicación del postulado de Taruffo a rubros específicos y particularmente polémicos.

4 Advertimos, con todo, que existe otro libro de recientísima data, en el cual participa como coautor: Taruffo, Michele; Andrés Ibáñez, Perfecto, y Candau Pérez, Alfonso, Consideraciones sobre la prueba judicial, Fundación Coloquio Europeo, Madrid, 2009, 172 p. Hemos proyectado hacer pronto una recensión de este nuevo aporte.

5 Pensamiento que está pronto a cumplir 40 años de desarrollo ininterrumpido, cuyo momento científico inicial podemos situar en el año 1970 con la publicación de la monografía Studi sulla rilevanza della prova, Cedam, Padova.

6 Hacemos notar que esta investigación ("Poderes probatorios de las partes y del juez en Europa") es la misma que aparece publicada en el sobredicho número 2 del volumen 12 de esta revista.

También hacemos notar que esta investigación ("Narrativas judiciales") aparece publicada en otra revista nacional: como ya lo mencionamos, está incluida en Revista de Derecho, Universidad Austral, Facultad de Ciencias Jurídicas y Sociales, 2007, vol. 20, N¹, pp. 231-270.

$8 \quad$ Es el artículo “¿Verdad negociada?", que al igual que el caso anterior, figura en Revista de Derecho, Universidad Austral, Facultad de Ciencias Jurídicas y Sociales, 2008, vol. 21, Nº1, pp. 129-151. 


\section{La prueba}

Taruffo, Michele. Marcial Pons, Madrid, 2008, 324 p.

(traducción de Laura Manríquez y Jordi Ferrer Beltrán)

A lo dicho es dable añadir, por último, que en la parte final del libro se incluye una completa bibliografía que enriquece la publicación, como quiera que proporciona un listado de los más importantes aportes existentes hasta la fecha en las doctrinas continentales y angloamericanas sobre la prueba.

Ahora bien, con el propósito de invitar a la lectura de esta obra, destacaremos tres puntos que nos parecen de especial interés.

El primero atañe a un aspecto que consideramos crucial para efectos de ponderar debidamente la doctrina de Taruffo en el rubro de la prueba y, más en general, del proceso. De inicio a fin, en este libro existe un mensaje fundamental sobre el sentido que tiene el proceso jurisdiccional y, dentro de éste, la prueba. En la primera parte, en efecto, se indica que en un Estado de Derecho, las decisiones judiciales deben ser "legítimas", es decir, "apropiadas y justas", "adecuadas y correctas", para lo cual se hace indispensable que la norma se aplique concretamente a los supuestos fácticos para los cuales fue concebida (pp. 22 y 23). En la segunda parte (anexos), a su vez, se expresa que no es suficiente que el modelo procesal entregue las vías para alcanzar la resolución de controversias; se requiere que las decisiones judiciales se sustenten en normas jurídicas aplicables al caso concreto, el que a su turno debe estar debidamente establecido en su dimensión factual, para que así el resultado no sólo sea formalmente aceptable sino intrínsecamente justo (pp. 176-181). Así pues, a partir de estas explicaciones podemos decir que la búsqueda de una verdad aproximada en lo fáctico no es tanto una meta del juicio, cuanto más bien una exigencia para la obtención de decisiones de calidad en términos de justicia. Esta acotación permite, a no dudarlo, aclarar una serie de cuestionamientos que parte de la doctrina procesal dirige en contra del objetivo de la búsqueda de la verdad factual.

El segundo se refiere al llamado de atención que encontramos durante todo el libro en torno a la necesidad de someter a crítica los antecedentes probatorios, para obtener de ellos una información relevante y jurídicamente admisible, y a la vez un sustento empírico adecuado para la decisión del conflicto. Especialmente categórico es el trabajo sobre la prueba científica (pp. 277-295), donde Taruffo enfatiza la importancia del control que deben hacer las partes y en especial medida el juez con respecto a las conclusiones que presenta la ciencia en las cuestiones sometidas a juicio; destaca algunos parámetros que deben considerar los tribunales para establecer la suficiencia de este tipo de probanzas y, sobre todo, a partir del precedente dado por la Suprema Corte estadounidense en el caso Daubert, subraya la necesidad de operar de un modo falsacionista, sometiendo a extrema crítica las opiniones de los expertos y velando por la validez y fiabilidad de los métodos empleados en este tipo de evidencias (pp. 283-285, 293-295). Así pues, con base en estas apreciaciones teoréticas, podemos decir que la prueba procesal no se compone de una exclusiva actividad de conocimiento; no constituye un ejercicio puramente epistemológico, ya que, desde luego, constituye un conocimiento institucionalizado en el marco de un debido procesal legal, por lo que los criterios cognoscitivos, si bien son los 
primeros que deben aplicarse, no son los únicos; pero, ante todo, es un conocimiento situado en un contexto de debate, por lo cual la mirada crítica de los litigantes y, ante todo, del juzgador, juegan un papel decisivo. Esta es otra acotación que puede servir para despejar las dudas que surgen en una materia tan compleja, como es la de la compatibilidad entre las perspectivas cognoscitivas y argumentativas de la prueba judicial.

El tercero concierne al estado de alerta que nos invita a mantener Taruffo a partir de las ideas que expone en el libro. No dejarse llevar por explicaciones irreflexivas sobre lo que implica la función adjudicativa; atreverse a replantear los conceptos que usualmente se manejan entre los teóricos del proceso en el campo de la prueba; dejar atrás la pasividad ante el sinnúmero de desafíos que en nuestros días plantea la tarea de resolver conflictos en el marco de un juicio, son algunas de las lecciones que entrega este texto.

Es por lo mismo que no podemos terminar esta reseña sin anotar lo meritorio que resulta para nuestro medio contar con revistas como ésta, que han servido de canal de comunicación de doctrinas tan relevantes como la de Taruffo. Nótese que tres de los cinco anexos del libro ya se encuentran publicados en revistas chilenas, y uno de ellos en ésta. Este es, en nuestra opinión, un suceso que tenemos que difundir y destacar, especialmente si consideramos que, como hemos dicho en otra ocasión, en un entorno tan formalista como el chileno, las invitaciones a abrir la mente hacia los desafíos del fenómeno probatorio, exigen ser divulgadas. Por esta razón, invitamos a leer este nuevo trabajo de Taruffo y, por supuesto, a seguir muy de cerca todos los avances dogmáticos que nos proporcionan publicaciones como Ius et Praxis. 